IdeAs

Idées d'Amériques

$12 \mid 2018$

Le tourisme dans les Amériques

\title{
Conversación con Iniquipili Chiari sobre el turismo en la comunidad Gunayala en Panamá
}

Discussion avec Iniquipili Chiari sur le tourisme dans la communauté de

Gunayala au Panama

Conversation with Iniquipili Chiari about tourism in the community Guanyala in Panama

Johanna Durget et Elodie Salin

\section{OpenEdition}

Journals

Édition électronique

URL : https://journals.openedition.org/ideas/4506

DOI : $10.4000 /$ ideas.4506

ISSN : 1950-5701

Éditeur

Institut des Amériques

Référence électronique

Johanna Durget et Elodie Salin, « Conversación con Iniquipili Chiari sobre el turismo en la comunidad Gunayala en Panamá », IdeAs [En ligne], 12 | 2018, mis en ligne le 18 novembre 2018, consulté le 18 octobre 2022. URL : http://journals.openedition.org/ideas/4506 ; DOI : https://doi.org/10.4000/ideas 4506

Ce document a été généré automatiquement le 18 octobre 2022

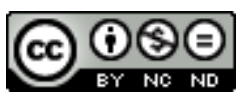

Creative Commons - Attribution - Pas d'Utilisation Commerciale - Pas de Modification 4.0 International - CC BY-NC-ND 4.0

https://creativecommons.org/licenses/by-nc-nd/4.0/ 


\section{Conversación con Iniquipili Chiari sobre el turismo en la comunidad Gunayala en Panamá}

Discussion avec Iniquipili Chiari sur le tourisme dans la communauté de Gunayala au Panama

Conversation with Iniquipili Chiari about tourism in the community Guanyala in Panama

Johanna Durget et Elodie Salin

\section{Entretien réalisé en octobre 2018 à Panama City}

Iniquipili Chiari

Johanna Durget 


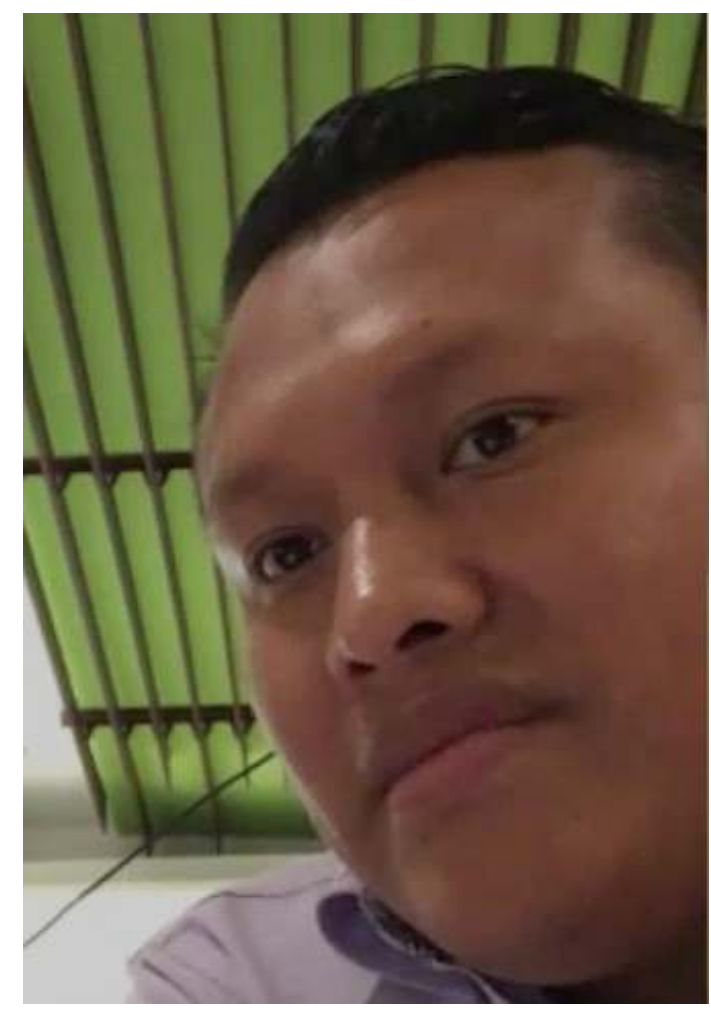

2 El encuentro y la conversación con Iniquipili Chiari en octubre de 2018 en la Ciudad de Panamá nació de la voluntad de dar la voz a los jóvenes del pueblo indígena de Gunayala en un contexto de desarrollo creciente del turismo, que ha generado impactos ambientales y sociales importantes.

Ubicada en la costa atlántica de Panamá, la comarca ${ }^{1}$ de Gunayala es una región indígena autónoma continental e insular marcada por conflictos políticos con el gobierno panameño. El desarrollo del turismo balneario inició a principios de los años 1930 y se intensificó en los años 1960, cuando el gobierno panameño inició su programa de promoción turística nacional e internacional de las 402 islas que componen este archipiélago de Gunayala. El modelo turístico de Gunayala está caracterizado por el control de las autoridades Gunas, quienes resistieron al turismo de masa ofrecido por los agentes externos (Estado panameño, empresas extranjeras) y se posicionan hoy como los únicos actores turísticos de la región (Martinez Mauri, 2010).

4 Iniquipili Chiari juega el papel de mediador entre el Ministerio de Ambiente (MiAmbiente) y los pueblos indígenas de Panamá, incluidas las autoridades de Gunayala (Congreso General Guna). Se ha enfocado recientemente en la creación de un órgano representativo de los jóvenes Gunas dentro de un sistema político muy jerárquico ${ }^{2}$. Para el pueblo Guna, el turismo está en el centro de un sistema económico dependiente y poco sostenible. A pesar de que existe un sistema de autogestión comunitaria original y estricto, el modelo de isla paradisíaca para un turismo balneario está muy poco cuestionado, y los impactos sociales y ambientales son significativos y preocupantes.

5 Iniquipili Chiari conoce ampliamente la cultura guna, y tiene un gran respeto por las costumbres y tradiciones de su pueblo. En esta entrevista, nos ofrece una mirada perspicaz sobre los retos de desarrollo turístico en la región de Gunayala, presentada por los medios de comunicación internacionales como un archipiélago amenazado por el cambio climático y la subida del nivel del mar. 
[La discussion issue de la rencontre avec Iniquipili Chiari en octobre 2018 à Panama City est née d'une volonté de donner la parole aux jeunes de la communauté autochtone Gunayala dans un contexte de mise en tourisme accélérée qui s'accompagne d'impacts environnementaux et sociétaux importants. Située sur la côte atlantique du Panama, la comarca ${ }^{3}$ de Gunayala est une région autonome continentale et insulaire autochtone marquée par des conflits politiques avec le gouvernement panaméen. Le développement du tourisme balnéaire, qui a débuté dans les années 1930 s'est accéléré dans les années 1960, lorsque le gouvernement panaméen cuvre à la promotion touristique nationale et internationale de l'archipel composé de 402 îles de Gunayala. Le modèle touristique de Gunayala est caractérisé par le contrôle des autorités gunas qui résistent à un tourisme de masse proposé par des agents externes (État panaméen, entreprises étrangères) et se positionnent comme les seuls acteurs touristiques de la région (Martinez Mauri, 2010). Iniquipili Chiari joue un rôle de médiateur entre le ministère de l'environnement panaméen (MiAmbiente) et les instances dirigeantes des peuples autochtones du Panama, dont la communauté Guna (le Congrès Général Guna). Plus récemment, il a œuvré à la création d'une instance représentative pour les jeunes au sein d'un système politique très hiérarchisét. Le tourisme pour la communauté Guna est au coeur d'un système économique dépendant et peu durable. Malgré un système d'autogestion communautaire original et très strict, le modèle de l'île paradisiaque pour un tourisme balnéaire est peu remis en cause et les impacts sociaux sur la communauté ainsi que les impacts environnementaux sont notables et préoccupants. Porté par une connaissance fine de la culture guna et un respect des coutumes et des traditions de son peuple, Iniquipili Chiari nous livre, dans cet entretien, un regard clairvoyant sur les enjeux du développement touristique de la région de Gunayala, donnée à voir par les médias internationaux comme un archipel d'îles menacé par le réchauffement climatique et la montée des eaux.]

Cabane

Christopher Weishaupt

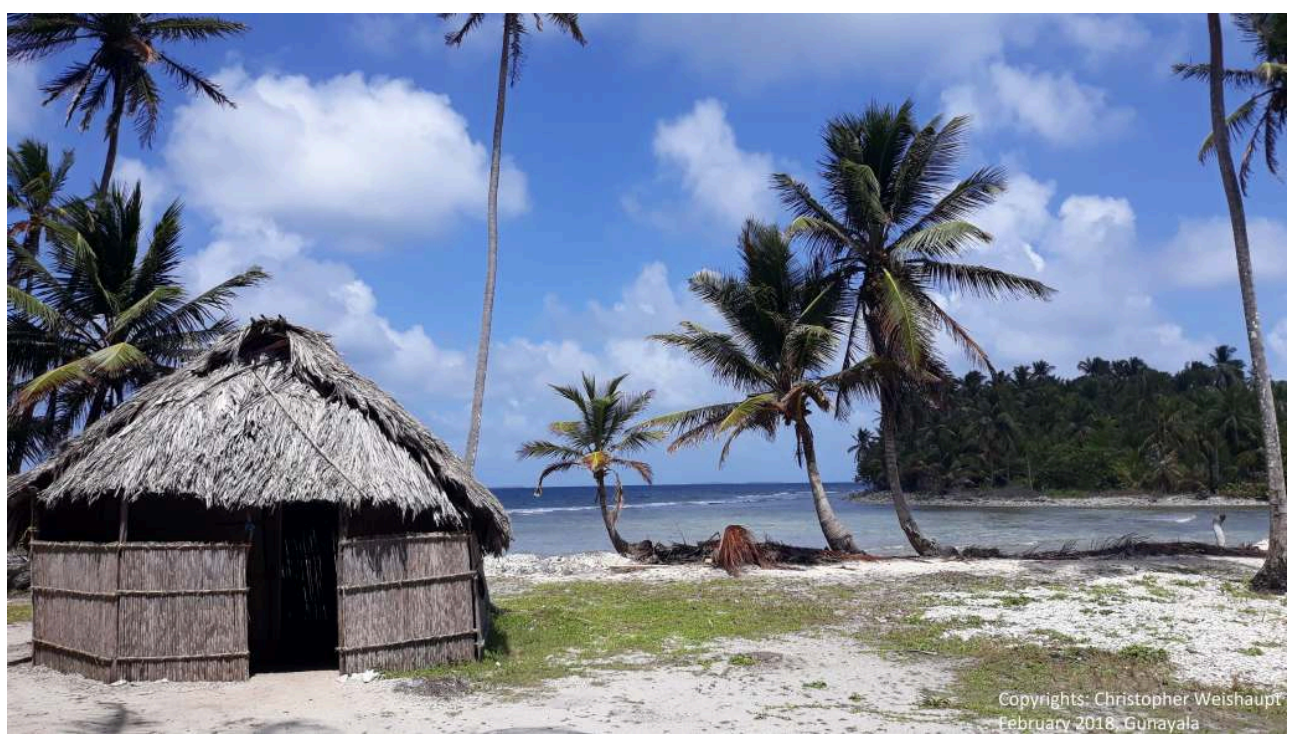

Johanna : Podemos iniciar esta entrevista con una breve presentación tuya : ¿De dónde vienes en Gunayala y cuál es tu papel hoy día en la comarca y más específicamente en tu comunidad? 
8 Iniquipili : Mi nombre es Iniquipili Chiari, que significa en idioma Guna «hacer las cosas correctamente » y como joven trato de honrarlo. Nací en la comunidad de Ustupu, que en español sería « la isla del ñeque ${ }^{5} »$. Normalmente en Gunayala las islas toman nombres de animales, pero también de sus características propias (manglares, corales). Nací allá y crecí allá, en la comunidad, y como todos en Gunayala por esa época llegábamos solo a noveno grado en la escuela local, me tocó venir a la capital para seguir con el décimo grado, y también para la universidad. Eso me dio la oportunidad de estudiar fuera, en Suiza, y allí fue más que nada el renacimiento del amor hacia mi cultura, hacía lo que yo soy. A veces, uno tiene que llegar lejos para darse cuenta de que lo más importante es lo que quedó atrás. Y eso es lo que pasó conmigo, estudiando turismo en Suiza. Un amigo mío me hizo una pregunta simple : si yo era indígena. Yo dije : « Sí, y mi nombre es indígena también. » ¿Y qué creen ustedes ? Es la pregunta que cambió todo en mí. Me di cuenta de que sí tenemos nuestras creencias, no quisiera llamarlo religión, sino creencias. ¿Qué somos? ¿De dónde vinimos? ¿Cuál es el objetivo del Guna aquí en el mundo ? Esas son las preguntas que me hacía. Tuve la oportunidad de quedarme en Europa, pero decidí regresar a mi tierra. Cuando regresé, empecé a trabajar más con los jóvenes, para crear un Congreso de la Juventud Guna, para que la juventud participará en las tomas de decisiones de las autoridades, encabezadas por el Congreso General Guna. Además de eso, el objetivo principal era que la juventud que tenemos hoy día en la comarca se enfocará en trabajar en el campo, conocer y practicar la medicina tradicional, los conocimientos tradicionales en general. Ese es el objetivo principal del Congreso de la Juventud Guna. Porque la realidad es que muchos líderes dicen que el problema son los jóvenes, pero justamente también como jóvenes podemos ser parte de la solución, si se hace de la manera correcta.

$9 \quad$ J : ¿Los líderes en Gunayala son siempre mayores, ¿verdad? ¿No hay jóvenes en las autoridades?

10 I : Lo que pude observar es que los jóvenes no quieren tomar iniciativas cuando se trata de cosas tradicionales. Entonces yo empecé una autoridad tradicional dentro de la comunidad, lo que es la primera fase. Para que los otros jóvenes pudieran imitar este ejemplo, para que vieran que las posiciones tradicionales no son menos. Porque para ellos era como extraño ver a un joven profesional, preparado, siendo una autoridad tradicional : ¿por qué lo hace ? Entonces eso era para enseñarles, presentarles, decirles : "Mira, estas posiciones también son importantes". La razón por la que en Guna Yala no hay jóvenes en las autoridades es que la primera fase, que es suaribed, fácilmente puede tomar de 15 a 20 años, lo que es escuchar, apoyar a los líderes... Cuando uno está todos los días con los líderes, escucha los cantos, las traducciones de los cantos, y uno va aprendiendo de cómo se lleva una comunidad, las mejores formas de tomar decisiones. 15 a 20 años después, se viene la parte de argar, que es el que es intermedio, es el que da consejos a la comunidad. El saila canta, el intérprete es el que da consejos a la comunidad. En general, es por medio del intérprete que llega el saila a la comunidad, a las mujeres, a los jóvenes. Y esa segunda fase puede tomar otros 15 a 20 años también. Entonces ya son entre 25 y 30 años en estas dos primeras fases para llegar a ser saila, que es un cargo vitalicio : normalmente es hasta que uno se muere. Eso significa que cuando llegas a ser saila tienes en general 60 años. Los abuelos dicen que es un proceso para aprender a llevar una comunidad.

11 Élodie : ¿Cuál es tu papel en el Ministerio de Ambiente de Panamá? 

Ministerio de Ambiente es tensa, porque el pueblo quiere su territorio. Entonces como técnico de Áreas Protegidas evalúo ese tipo de situaciones, y a veces podemos tener acciones internacionales con la Corte Interamericana y el Estado. Es posible darles "comarcas" y tierras colectivas a los pueblos indígenas. No chocan los términos legales que dice la Unesco. Muchos de estos territorios que piden los pueblos indígenas están dentro de las reservas de la biosfera. Por ejemplo, hoy en día una de las comunidades Nasos está pidiendo alrededor de 150.000 hectáreas que están dentro del Parque Nacional de la Amistad, y eso es un sitio que fue declarado patrimonio de la Humanidad. Y otro pueblo mío pide lo de la reserva del Tapón del Darién, donde están dos comunidades Gunas. ¿Cómo pueden convivir estas dos cosas? A mí me toca estar allí en todo el proceso, porque conozco la parte tradicional, cultural y de lucha de los pueblos indígenas, y tengo también la parte técnica del Ministerio, la parte legal. Esta situación me hace decir que los pueblos indígenas sí conviven con la naturaleza, sí se puede. Simplemente también hay que tener voluntad. están haciendo inspecciones de campo por las solicitudes de tierras colectivas de los hermanos Emberás. El Ministerio está haciendo ahora mismo giras en los campos con ellos, para determinar qué tipo de ecosistema hay, y hacer el proceso de titulación. Esa comunidad convive con los manglares, convive con el bosque, no deforestan. Desde el punto de vista técnico, nosotros vemos eso como ganancia, porque no tenemos suficientes guardaparques y ellos solitos defienden su tierra.

É : Muy interesante. Sobre el tema del turismo, que es nuestro enfoque en este artículo, la primera pregunta que tendríamos sería si podrías describir el tipo de turismo que se encuentra en Gunayala. ¿Que existe ahora y cómo funciona?

I : Puedo hablar en porcentaje. Puedo decir que el $90 \%$ del turismo en Gunayala es de sol y playa. Hay comunidades más alejadas del sector turístico que tienen cabañas como las de Uggubpseni. También hacemos turismo con los hermanos colombianos, pero es al otro lado de la comarca en la frontera con Colombia. Gunayala. En este sector hay muchas islas. Y de lo que conozco, solamente hay una o dos personas que trabajan con turismo cultural, que se presenta con un paquete : pasas por el área protegida, llegas al puerto, vas a la comunidad, ves su danza, compartes cómo viven, y al final tienes la parte de playa. Pero normalmente casi todos van del puerto directo a la playa. Para muchos turistas no es importante eso de ver la parte cultural. Pero eso también puede venir de una debilidad de nuestras secretarías de Turismo en cuanto al turismo cultural, que se está desarrollando poco a poco.

E : ¿De dónde vienen los turistas a Gunayala y cómo llegan a la comarca?

I : La mayor parte de los turistas son extranjeros y vienen de todos los lados del mundo : Europa, Estados Unidos... pero no hay muchos de Suramérica. Ahora con las relaciones con China, también han empezado a venir turistas chinos. La razón por la que mucha gente va a Gunayala es que está cerca de la ciudad capital (Ciudad de Panamá) : a dos horas y media en carro por la carretera de Llano-Carti. Es la única carretera que tenemos en nuestro territorio y puede explicar que, por ser la única, 
todos vayan a la zona de Carti (zona turística). Es una cuestión económica: es más barato llegar por la carretera que por las avionetas que salen de la Ciudad de Panamá hacia otras comunidades, como Uggubseni o Ustupu. Estas comunidades no reciben muchos turistas porque están más alejadas. Y por eso también hay menos impacto del turismo allá.

$\mathrm{J}:$ ¿Cuáles fueron los impactos de la construcción de la carretera del Llano-Carti sobre la comunidad y el turismo de la comarca de Gunayala?

I : Esta carretera generó unas cosas buenas y otras malas. En los años 1950-1960 se abrió la carretera gracias a los fondos propios de los Gunas que trabajaban en la Zona del Canal manejada por los EEUU. Todos los Gunas que trabajaban allí aportaron dinero a la comarca y así fue que se abrió la primera trocha. Con esa apertura del territorio llegaron los colonos (así se les dice a los que no son Gunas) a invadir nuestro territorio, y eso trajo un conflicto grande en aquella época. Los jóvenes iban a hacer patrullaje en estas zonas de la comarca y hubo enfrentamientos. La parte del territorio que los Gunas perdieron la pudieron recuperar más tarde. Descubrimos hace poco que todavía hay gente no Guna que tienen título de propiedad en la comarca, lo que normalmente está prohibido. Por estas irregularidades de títulos estamos ahora en litigio en la Corte...

El turismo era poco en esa época, porque aunque había una trocha, la carretera no permitía un acceso fácil. Los visitantes llegaban por mar, en cruceros que anclaban cerca de las comunidades. Hoy en día, desde que la carretera fue pavimentada completamente en 2011, vienen menos cruceros y la mayoría de los visitantes llegan por tierra.

É : ¿Y hay una voluntad de desarrollar ecoturismo en Gunayala ?

I : No se ha planificado eso a largo plazo. Lo que se está haciendo a nivel turístico en Gunayala es la creación de normas para regular el turismo existente. No hay un programa del mismo Congreso General Guna que trabaje en los objetivos del turismo a futuro, porque solamente se está trabajando en los problemas de ahora.

$\mathrm{J}:$ ¿Existen cifras sobre los ingresos del turismo en Gunayala?

27 I : Al analizar el ingreso económico de la comarca, vemos que lo que le permite funcionar es el turismo, por el pago de entradas a las Áreas Protegidas. Entre $75 \%$ y $80 \%$ de los 2 millones de dólares (USD) que genera Gunayala al año vienen de los impuestos del turismo. Entonces sí, puedo decir de manera segura que esta es la columna vertebral que permite a las autoridades de la comarca ser autónomas.

E : ¿También hay una reglamentación para entrar en las aguas de la comarca?

I : Sí, se les cobra igual a los que entran por el mar y a los que entran por tierra. Son 20 dólares por persona más el impuesto del barco. Por vía marítima, llegan los veleros y los cruceros. Los cruceros no hacen problema con este pago, ellos siempre pagan sin discutir. Solo son los veleros que generan más problemas.

$\mathrm{J}:$ ¿Entonces se podría decir que hay una dependencia hacia el turismo ?

I : Correcto, y una dependencia muy fuerte. Tener esa dependencia y, además, tener problemas con el Estado puede ser un peligro importante para Gunayala. Por ejemplo, hace un par de años la comarca fue afectada por la llegada del virus $\mathrm{Zika}^{7}$ a América Latina. El turismo bajó notablemente y el ingreso de la comarca también, tanto para el Congreso como para los que trabajan en el sector turístico. Es todo un círculo. Y 
entonces estuvimos en números rojos en la parte económica. Eso indica que sí dependemos mucho del ingreso del turismo.

\section{Cocotiers}

ANNE GEgg

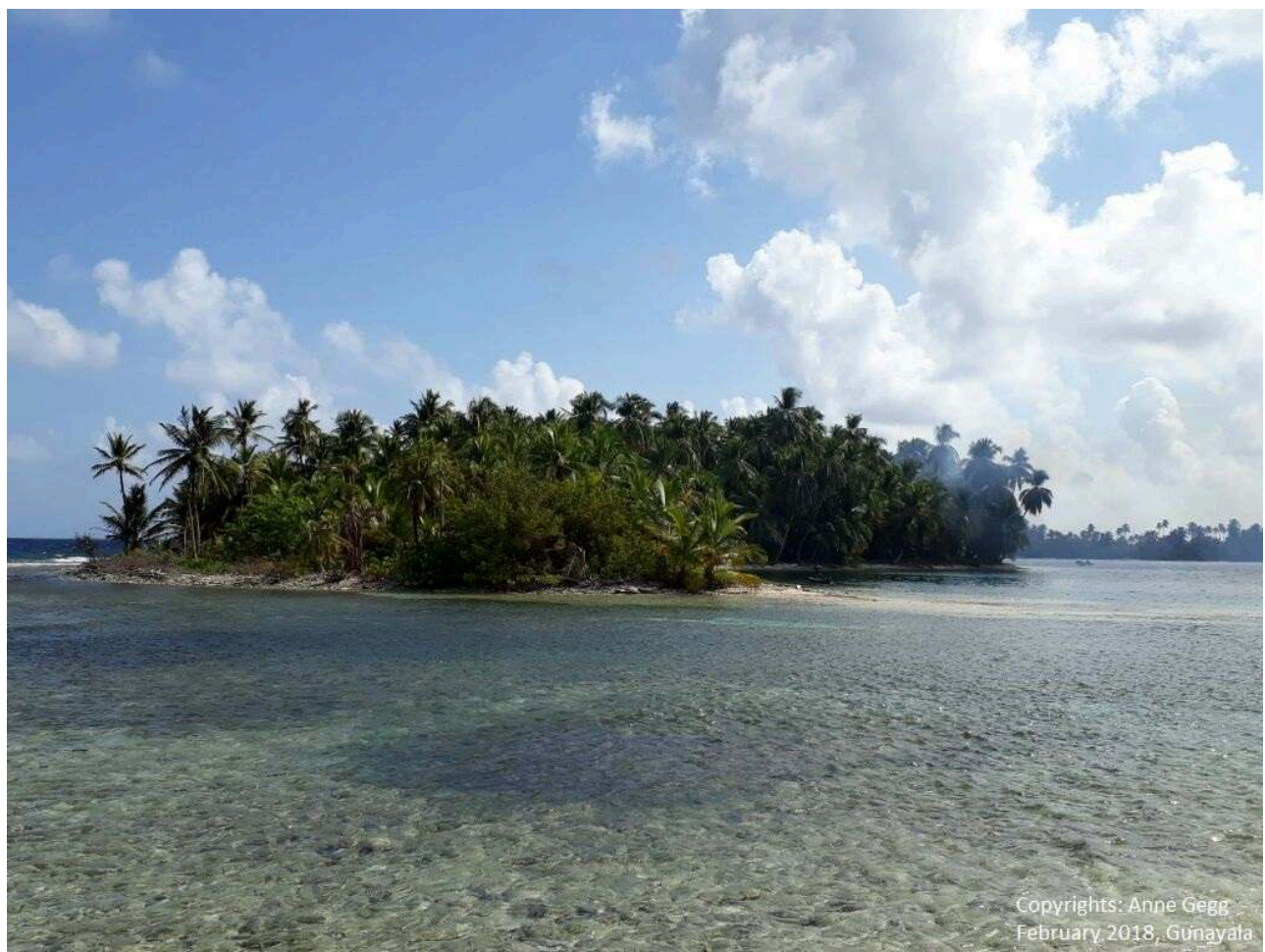

É : ¿Cuál es la especificidad del modelo turístico de Gunayala?

I : El modelo turístico de Gunayala necesita todavía mejorarse, en particular en lo relacionado con el sistema de impuestos, que está muy dividido. Uno normalmente va a un país y puede pagar un paquete donde todo está incluido. En Gunayala no es así. Primero, el visitante tiene que pagar un impuesto del Congreso General Guna para entrar al Área Protegida, en el peaje del puesto de control que se encuentra en la frontera de la comarca. Luego, el visitante llega a los puertos de la costa y como estos pertenecen a una comunidad, también hay que pagar un impuesto. Y al llegar a las islas, toca pagar también, porque las islas pertenecen a una familia. Entonces el visitante se pregunta por qué le cobran a la entrada, en el puerto y también en la isla. Y claro, eso genera un poco de desconfianza en los visitantes. Ahí la debilidad viene del mismo Congreso General Guna y de las autoridades que trabajan en el sector turístico, porque no explican la razón por la cual se les cobra a los turistas por entrar al territorio de Gunayala, en el puesto de control de la carretera, 20 dólares a los extranjeros y 5 dólares a los residentes de Panamá.

J : Entonces, ¿por qué el Congreso General Guna no explica estos impuestos? Se ha escuchado de la parte del gobierno panameño y en unas revistas nacionales que es "ilegal" de la parte de los Gunas eso de "cobrar la entrada a su territorio" final no es cierto porque las autoridades Gunas cobran por la entrada al Área Protegida y no propiamente por la entrada al territorio Guna. ¿Acaso ese tema no tiene un 
impacto sobre la experiencia del visitante, pero también sobre la autonomía Guna en sí?

I : Sí. Bueno, es cierto que la parte de la experiencia que se lleva el turista tiene también un impacto de alto valor para el turismo de Gunayala. A nivel nacional, la situación ha quedado un poco más clara, aunque falta mucho para explicar las razones por las cuales se cobra la entrada. Lo que pasa es que en Panamá se piensa que este cobro es para entrar a la comarca y entonces dicen que cuando la gente de la comarca viene a Panamá, esto no se cobra. No está claro que es un Área Protegida, legalmente declarada por el Ministerio de Ambiente, pero bajo la administración del Congreso General Guna. El Congreso tiene diferentes secretarías y una de estas es la Secretaria de Turismo, cuyo enfoque es velar sobre el cumplimiento de las normas turísticas en Gunayala. Pero una de sus debilidades es que no entrega información a los visitantes sobre el sistema de impuestos por ejemplo.

E : Hablando un poco de la historia del turismo en Gunayala, ¿cómo podemos explicar que no existen hoteles lujosos y grandes en las islas? ¿Cómo fue que las islas resistieron a este tipo de turismo?

I : Hubo propuestas para que se pudiera hacer hoteles tipo "resorts". Pero en la época, los líderes supieron que este proyecto no era un beneficio para ellos y que quedaba fuera de su capacidad. Además, supieron que sus hijos quedarían trabajando para personas que no eran Gunas. Por eso podemos encontrar en las normas internas de la Comarca Guna Yala ciertos artículos que dicen que las únicas personas que pueden hacer una inversión en la comarca son los mismos Gunas. Hubieran podido cambiar las reglas, pero no quisieron. $Y$ esa fue la primera barrera que defendió la comarca contra la inversión extranjera. Por esa época, llegaban incluso ministros del Estado a ofrecer ese tipo de propuestas de "resorts". Rubén Blades, cuando era Ministro de Turismo de 2004 a 2009, llegó a Guna Yala con una propuesta de este tipo. Les voy a contar una anécdota de lo que le dijo el cacique a Rubén Blades en ese momento: "Yo tengo un cayuco, yo sé lo que mi cayuco puede cargar : cocos, plátanos..., y no puedo abusar de este cayuco. Si yo le pongo mucha carga, mi cayuco se voltea o se hunde y yo pierdo todo. Lo que tú me traes como desarrollo no es el desarrollo que yo conozco, no es para mí. Lo poco que tengo lo puedo perder todo, entonces no quiero estos millones de dólares de inversión que quieren hacer". Hay que saber también que anteriormente los líderes eran más duros y estrictos en proyectos, no eran muy abiertos.

E : Ahora existen varios proyectos turísticos (alrededor de 50). ¿Qué tipo de proyectos son entonces?

I : Hoy los proyectos turísticos son manejados por los propios Gunas. Ahora muchos son profesionales, entonces tienen acceso a préstamos, y así más Gunas se pueden dedicar al turismo. Algunas islas tienen muchos dueños que hacen una inversión juntos para construir sus cabañas, comprar sus lanchas y carros. Hoy en día ha crecido ese tipo de turismo de cabaña, sol y playa, por decirlo así, en el sector de Cartí más que nada, por el ingreso que tienen los propios Gunas que trabajan en la ciudad y que tienen acceso a préstamos. La Secretaría de Turismo está tratando de dar seguimiento porque como Guna uno tiene que presentar de dónde proviene su inversión económica al Congreso General Guna. Cada uno tiene que presentar los papeles del préstamo y mostrar de dónde viene la inversión. Eso se hace en parte a causa de la presencia del narcotráfico que genera lavado de dinero en la comarca. 

tiene en los ecosistemas. Muchos han talado el manglar para poner su negocio porque no está regulado. La relación del pueblo Guna con el manglar ha sido la siguiente: primero, se usa para la leña (pero ya cuando están secos); segundo, es para construir las casas ; tercero, para la pesca. Un secreto de los pescadores Gunas es que siembran un manglar, cada uno en un lugar determinado en el mar, y saben que ahí van a venir los peces y va a haber vida marina. Así, cada vez que se van a pescar, ya saben a donde está su "supermercado". Pero en las normas internas de la comarca no hay nada escrito para la protección del manglar. El Congreso General Guna no tiene una secretaría del Ambiente que pueda analizar los impactos ambientales cuando se quiere hacer un proyecto : localización y tamaño del proyecto, cuál es el ecosistema (encima de la arena, manglar, arrecife)... Ahora es la Secretaría de Turismo la que analiza ese tipo de proyectos y los eventuales impactos ambientales, pero no tiene la capacidad de hacer un análisis profundo.

$41 \mathrm{~J}$ : Teniendo en cuenta la fuerte presión demográfica que hay en las islas comunitarias de Gunayala hoy día, ¿existe también un problema de capacidad en las islas turísticas y en la comarca en general con la llegada de turistas? Por ejemplo durante las fiestas patrias en Panamá...

I : Para mí es un problema. Las fiestas patrias son un buen ejemplo. Muchas de las personas que tienen un negocio turístico no tienen un inspector de la Secretaría de Turismo y entonces albergan muchos más clientes de lo que permite la capacidad de la isla. El problema viene primero con el transporte. Los que tienen lanchas no tienen esta responsabilidad de hacer el viaje de ida y vuelta con los turistas, y muchas veces solo quieren conseguir dinero, nada más, pero al final cuando es la hora de salir, los turistas no tienen lancha, no hay carro para regresar a la ciudad capital, y esto se vuelve problemático. Segundo punto, el problema es también en las islas. Estamos hablando de islas pequeñas donde casi no hay fuentes de agua. Cerca del $98 \%$ de las islas turísticas no tienen una fuente de agua, como un pozo. Entonces se va a buscar agua al río, en tierra firme. Pero si tu isla es muy pequeña con una capacidad de 25 personas y que metiste 50 personas, ¿qué pasa? Tienes problemas para el agua, el uso de baños, la comida, el transporte... Y eso trae incomodidad a los visitantes. Y los visitantes al mismo tiempo pueden generar incomodidad si ponen la música fuerte, por ejemplo. La logística en general está comprometida por el carácter insular, aún más si no se respeta una capacidad de visitantes razonable. Por ejemplo, alimentar a muchos visitantes puede ser un problema y entonces la experiencia del turista se puede ver afectada también. Pero, de todos modos, muchos aceptan más visitantes de los que pueden recibir porque es un ingreso importante en el momento, y también por falta de control del Secretaría de Turismo.

É : Entonces vemos que la experiencia del turista puede ser comprometida en varias ocasiones. ¿Esto afecta a la imagen turística de Gunayala y tiene un impacto en el sector turístico?

I : La experiencia del turista se podría tasar con las páginas web como TripAdvisor, por ejemplo. Pero hasta ahora no se ve el impacto de estas malas experiencias, el turismo es muy dinámico todavía en Gunayala. Sí bajó en el tiempo del virus Zika. Pero, hoy en día, en todo Panamá hay un turismo bajo, no es solo un problema de Gunayala.

$45 \mathrm{~J}:$ ¿Cuáles son los desafíos más preocupantes a nivel ambiental en la comarca de Gunayala ? ¿El turismo causa o exacerba estos desafíos? 
I : Hay dos tipos de problemas: ambientales y culturales. En lo que respecta a problemas culturales, el turismo aparece como un ingreso mucho más rápido para los que trabajan en ello, en comparación con las otras actividades económicas. Esto provoca que los jóvenes hayan dejado de pescar hoy en día, y que los adultos hayan dejado de trabajar en el campo. ¿Por qué ? Porque ya hay un ingreso en el pueblo. Por ejemplo, los que acompañan las lanchas turísticas ganan 25 dólares por día. ¿Por qué trabajar en el campo, por qué ir a pescar si tengo un ingreso más rápido y fácil ahí ? Eso tiene un impacto bastante grande en las comunidades de Gunayala. Esta situación de deserción del trabajo de campo o de la pesca frente al turismo la podemos ver en las comidas que sirven en las islas turísticas, como los plátanos o los mariscos : te puedo asegurar que los trajeron de afuera de Gunayala. Los productos no son locales, solo hay uno o dos productos locales en las comidas. En el caso del pescado, muchas veces engañan a los turistas. Los mariscos vienen de afuera. La cosa es que no hay quien lo pesque. Muchas veces podrías ver en un viaje de la capital hacia la comarca que llevan paquetes de camarón. El turista piensa que viene de aquí, pero no es el caso. En realidad, pocos están trabajando la tierra.

Por ejemplo, mi tío vive en la primera isla que está al frente del puerto de Carti. Él se dedica a vender pollo y vegetales que vienen de la capital en su tienda y tiene muchos clientes por este tipo de productos que vende. Su objetivo es dejar de comprar de la ciudad, producir en su propia finca y vender sus productos. Es una inversión costosa que no es a corto plazo sino a largo plazo. Esos son quizás tipos de proyectos que faltarían para las personas que quisieran trabajar en el campo o en vender productos locales.

Por el lado de los problemas ambientales, el impacto visual más importante son los plásticos, es decir la basura. En todo Panamá están haciendo una ley para regular los plásticos. Pero todavía no tienen esa cultura de reciclar. La realidad es que son muy pocos los visitantes que van a la comarca y que traen de vuelta su basura consigo. ¿Y adónde va la basura que se queda en la comarca? Al mar. El pueblo Guna está acostumbrado a tirar todos sus desechos al mar porque antes estos desechos eran solamente orgánicos (pescado, plátano, coco). Pero hoy en día son latas, botellas, plástico, baterías, pero aún mantienen la costumbre de tirarlo al mar.

\section{Baignade}

ANNE GEgg 


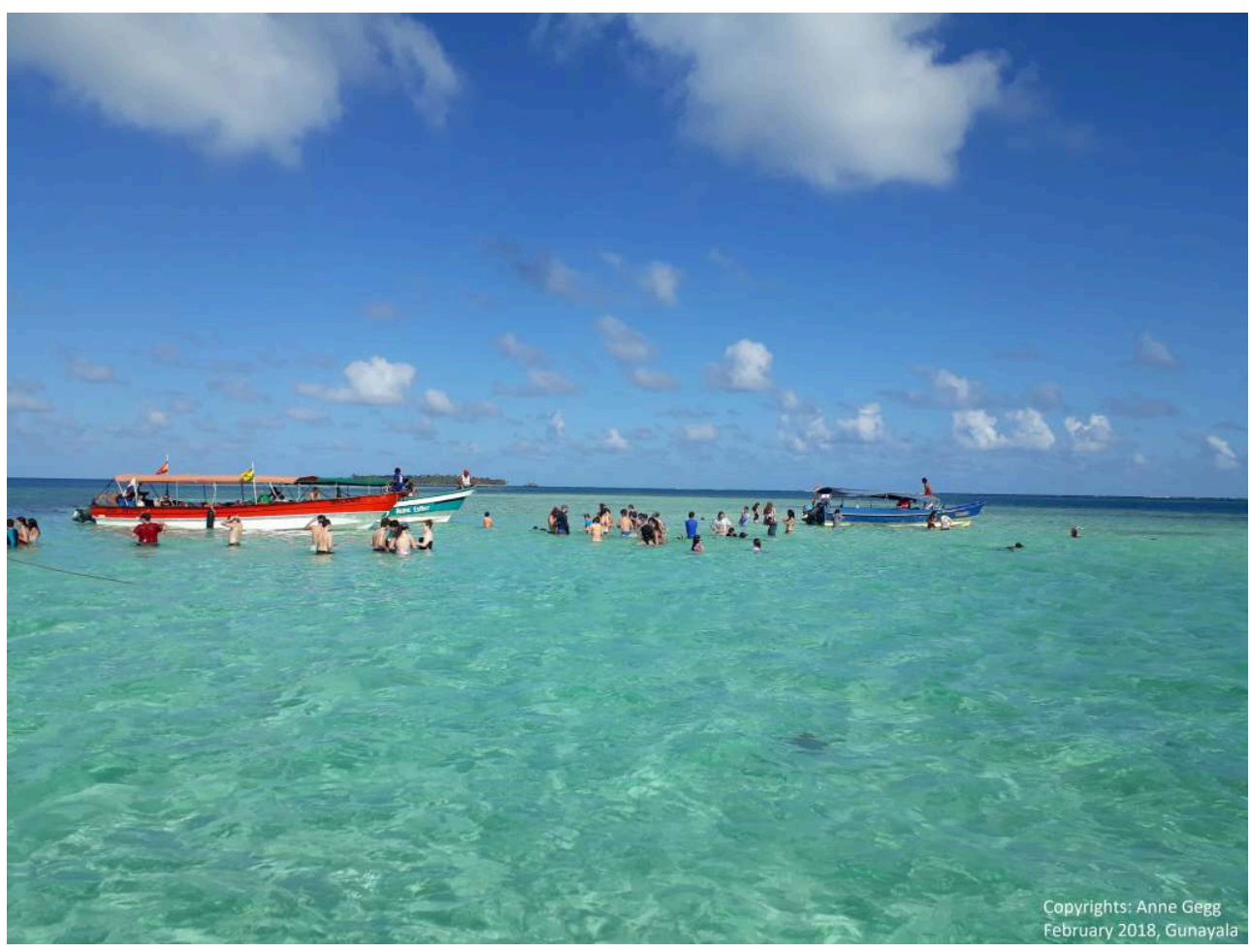

$\mathbf{J}:$ ¿Existen unos problemas ambientales que impactan directamente al sector turístico? Por ejemplo, unas islas turísticas tienen unos arrecifes maravillosos y otras tienen arrecifes muy dañados... ¿Este fenómeno tendría impacto en la experiencia del turista?

I : Primero, para comprender ese tipo de situación tienes que ver lo que ve el Guna en la naturaleza. En general, los Gunas cuidan más el bosque, pero menos la parte bajo el agua o los manglares. Quizás viste un cayuco llegando a una isla y vendiendo langostas : ¿de dónde salen estas langostas? Vienen de los corales. El Guna sabe que es un buen negocio vender langostas porque trae un ingreso muy alto y porque hay una demanda alta por parte de los turistas. Las langostas están generalmente dentro de los corales, y el pescador va a quebrar el coral para poder atraparlas y venderlas. Lo que pasa también es que, además de matar el coral, sales con un pedacito pequeño de langosta que no llegó a la etapa de reproducción... Eso tiene un impacto muy fuerte. Otro elemento también es el tamaño de las islas : hay muchas comunidades Guna que viven en islas chiquitas y redondas. ¿Y cómo haces para enfrentar al crecimiento poblacional de la comunidad isleña? ¿Cómo rellenas? Utilizas corales vivos y cascajo del río para agrandar la isla. Entonces el impacto que tiene en los arrecifes coralinos es muy alto. Y es ahí que deberían entrar los otros actores a trabajar para explicar la importancia que tienen los corales en la población Guna. La importancia de los manglares, la importancia de no coger todas las langostas, etc.

$51 \quad \mathbf{J}:$ ¿Faltan profesionales que trabajen en el medio ambiente y programas de educación en Gunayala, entonces?

I : Pienso que la creación de una Secretaría de Medio Ambiente en la comarca es algo urgente. Ahora la Secretaría de Turismo también se encarga de temas ambientales, pero no tiene personas capacitadas realmente para hacerlo. Y hoy en día no es la prioridad para las autoridades de la comarca, ellos tienen otros tipos de preocupaciones como la interconexión eléctrica que quiere pasar en la comarca. Por eso, trabajar con los 
jóvenes es algo importante. De los jóvenes que se juntaron para el primer Congreso de la Juventud Guna, muchos van asistiendo al Congreso General Guna y ahí se podría ver la creación de una Secretaría de Medio Ambiente. Creo que esta iniciativa saldría de la voluntad de los jóvenes. Los que van a Gunayala son más de playa y sol. Tampoco existe algún tipo de programa o iniciativa de pesca turística en Gunayala. También hay que saber que son actividades que son únicamente para los Gunas. Por ejemplo, los que utilizan el arpón son solos Gunas. A los visitantes (no Gunas) no se les permite pescar con arpón, es prohibido en la comarca. Son reglas de la comarca. Pero si uno viene a la comarca y tiene amistad con unos Gunas, y se queda en una comunidad, en general sí puede llegar a tener este tipo de experiencias. En estas ocasiones uno puede ir al campo con los Gunas del pueblo, ir a pescar... Por ejemplo, yo he llevado amigos a mi comunidad y he pedido permiso a mi comunidad para que mis amigos vayan a bucear o pescar con arpón, o para que vayan con pescadores Gunas a ver cómo atrapan las langostas $u$ otros animales marinos...

I : Existen diferentes percepciones, pero no diría entre los jóvenes y ancianos, sino más bien entre las regiones de la comarca. Hay unas comunidades que tienen un ingreso alto por el turismo y otras que no tienen este ingreso. Para los que están en la zona turística, el turismo es muy importante. Hay unas comunidades en donde todos están trabajando en el turismo. Pero igual, siempre existen una o dos personas que no tienen relación con el sector turístico y que mantienen su diario vivir en el campo, por ejemplo. Las que no tienen un ingreso por el turismo es por que están ubicadas al este de la comarca, más lejos de los puertos principales. Son comunidades que trabajan en el campo y en la pesca, por ejemplo. Y las comunidades costeras de la comarca tampoco 
reciben muchos turistas. Ya más cerca de la frontera con Colombia hay otro tipo de turismo.

$61 \mathrm{~J}:$ ¿Los sailas ${ }^{9}$ también son actores en el sector turístico ?

62 I : Sí, hay algunas autoridades que sí. Hay que saber que algunas islas pueden tener hasta 80 dueños. Y unos de los dueños puede ser el saila. Entonces, en este caso, las regulaciones sobre el turismo pueden ser flexibles, pero para los demás Gunas (por ejemplo, los que llevan lanchas), las normas son más rígidas. Cada actor turístico Guna tiene su certificado emitido por la Secretaría de Turismo, como los guías, los que llevan lanchas, los operadores de turismo, etc. Ahí, el Congreso General Guna sí mantiene un tipo de control. Pero en temas más generales, como la orientación que le queremos dar al turismo en Gunayala (a dónde queremos llegar con él o qué tipo de turismo queremos ofrecer) y en temas de educación ambiental, no hay planificación o control.

J : ¿Los Gunas del sector turístico de Carti están satisfechos con el turismo ? ¿Cuál es la opinión de las comunidades que se encuentran al margen de la economía turística?

I : Sí puedo decir que la mayoría de las personas están felices con el turismo porque les genera un ingreso muy alto. Podría decir que el enfoque de las comunidades del este es diferente al enfoque de las comunidades del sector Carti. Las comunidades más aisladas al turismo se enfocan en proyectos que desde mi punto de vista son más sostenibles, como el trabajo en el campo. Entre más te alejes del sector turístico, más vas a ver elementos culturales y tradicionales como la convivencia en la comunidad. En el sector turístico, el visitante tiene que pagar por todo, por sacar una foto, por tomar un coco... Pero en el otro sector, más hacia el este, no va a tener que pagar por esas cosas. Se recibe al visitante de manera muy diferente en estos sectores de la comarca.

$\mathrm{J}$ : Las relaciones son más económicas entre el visitante y el Guna en el sector turístico que en el sector del este, entonces...

$\mathrm{J}$ : La mola ${ }^{10}$ se convirtió en un símbolo internacional de la cultura Guna, su comercialización es transnacional. Pero pude ver que en las comunidades de la comarca las jóvenes Guna no usan mucho la vestimenta tradicional con la mola. Por un lado, el turismo promueve el arte de la mola, pero, por otro lado, parece que este arte desaparece en las comunidades, ¿no?

I : Esto es un fenómeno general, no es solo el turismo el que lo causa. Nosotros nos movemos mucho de la capital a la comarca. Los jóvenes ven el tipo de ropa que la gente se pone en Panamá y tienen pena de usar su mola en la ciudad, porque muchas de las personas los miran extraño. Esto es una de las razones. Igual pasa con los nombres, yo casi cambié mi nombre Iniquipili porque en la escuela tuve problemas de "bullying" por eso. La única razón por la que no lo cambié es porque a mí me gustaba mi nombre, mi cultura... Imagínate los jóvenes que no tienen estos mismas valores hacia su cultura o estos mismos conocimientos. Mi primo se llamaba Iniquilapi, ahora se llama Carlos Javier. Se cambió por la presión que había. Igual pasa con la mola, los jóvenes hoy en día que vienen a estudiar a la capital, cuando regresan jamás se vuelven a poner su mola. Porque ya se sienten extraños de convivir así en la capital. Pero las mujeres que vivieron en las comunidades toda su vida sí se ponen sus ropas tradicionales, porque son personas que no salen de la comarca. Solamente en las comunidades costeras, más allá de Ustupu (sector este), es donde las mujeres desde muy jóvenes empiezan a 
ponerse el vestido tradicional como deberían. Pero es mucho menos el caso en las comunidades turísticas.

La mola es un ingreso muy importante para las familias. Por ejemplo, la mamá de mi esposa trabaja vendiendo mola, es su ingreso y con eso mantiene a la hija que está en la universidad, porque solamente con el ingreso del papá no se puede. La mola es un aporte muy importante en las familias.

É : ¿Cuál es el papel de la mujer en el turismo, entonces?

71 I : En cada isla turística donde vayas, siempre vas a ver a una mujer trabajando allá, vendiendo mola o trabajando de mesera, pero en las comunidades, como pocos turistas vienen, pocos compran la mola. Y las personas que tienen islas turísticas son las que venden las molas. Así que en las comunidades hay menos ingreso por la mola que en las islas turísticas.

É : ¿Entonces cómo se hace el encuentro entre turistas de playa y la comunidad?

73 I : La manera en que el visitante va a tener un contacto con las comunidades puede ser de diferentes maneras: aunque hay pocos guías que llevan a los turistas a las comunidades, esto es una primera manera de encontrarse con los comuneros Gunas. Segundo, el contacto se puede hacer con los Gunas que trabajan en las islas turísticas, y que al final son parte de una comunidad también. En la mayoría de los casos, los turistas se encuentran con los Gunas en los puertos, en las islas turísticas o en la carretera Llano-Carti, pero no tanto en las comunidades mismas, a menos que los turistas mismos elijan ir hasta allá.

Como hay muchas islas turísticas, tiene que haber muchas personas que trabajen en el turismo. Hay también una parte de los Gunas que se está enfocando en el turismo con los veleros. Por ejemplo, las mujeres están involucradas en la venta de mola con los veleros. Van con su lancha de velero en velero para vender sus molas.

También está el caso de las mujeres de las comunidades que no tienen algún tipo de conexión con alguien que tiene un negocio turístico o que es dueño de una isla turística, entonces no tienen ese tipo de ingreso con la mola como otras.

É : ¿Hay Gunas que no tienen nada que ver con la actividad turística en la comarca?

I : Hay, pero son pocos. Son pocos los que se dedican al campo todavía y que no trabajan con el turismo. Es complicado para ellos con el sistema que hay en este sector, porque las cosas son más caras por ser un sector turístico.

É : ¿Y cuál es la situación con el narcotráfico en la comarca?

timosamente es una realidad que vivimos en la comarca. La droga en Gunayala está por todos lados, porque estamos cerca de Colombia. Las lanchas llenas de droga pasan a alta velocidad por nuestras aguas y a veces tienen que tirar bolsas de droga al mar para que la policía panameña no los agarre con esto. Y son los Gunas de la costa los que reciben todo y lo vuelven a revender a los colombianos. Pero no todo se vende, tal vez un $5 \%$ se queda en la comarca y circula para la venta interna. Y también se vende en Panamá. Con relación al turismo, podemos decir que hay islas turísticas que reciben jóvenes y que este tipo de actividad existe, pero no en todas. Antes del turismo, ya teníamos esta situación de narcotráfico. Pero con la llegada del turismo, sí podemos decir que el consumo del alcohol ha aumentado, porque hay más ingreso para comprar ese tipo de cosas. Eso trae problemas en las familias Gunas.

É : ¿Entonces hay diferentes tipo de turismo según las islas? 
81 I : Sí, esto tiene que ver mucho con el precio. Un turista que quiere pasar un fin de semana tranquilo con su familia va a una isla tranquila, donde el precio puede ser un poco más alto y donde hay más privacidad. Las islas turísticas que proponen precios más económicos reciben más a los jóvenes, en general. Por ejemplo, hay islas turísticas como la de Yandub que son más cómodas y de precio más alto (alrededor de 100 dólares por noche), y como está aislada de Carti llegas en avión también, lo que es más cómodo que el viaje por carretera. En las islas de precios más bajos, la acomodación es menos cómoda, tal vez es compartida, en una infraestructura de madera con varias habitaciones. turística que tiene 80 dueños, y para tomar una decisión es muy complicado. Las personas acaban peleándose. A veces protestan porque no les gusta la forma en que se está administrando la isla turística, dicen que la persona o la familia encargada está haciendo mal administración, y la sacan. Después viene otra, y es la misma situación. Hay mucha desconfianza y ha habido problemas entre familias. También, y se vuelve aún más complicado, una isla turística puede pertenecer a familias de diferentes comunidades. También hay islas turísticas que tienen un dueño nada más, pero son muy pocas, creo que hay menos de 5 islas así en el sector turístico de la comarca. La mayoría son compartidas (40 dueños en promedio). Los conflictos así terminan casi siempre en el Congreso General Guna : se presentan a toda la Asamblea cuando las familias no logran resolver el conflicto de manera interna. Por ejemplo, cuando la persona que alquila la isla turística para manejar el negocio no paga como se había acordado entre los dueños. A veces también dos grupos de familias se pelean para administrar la isla. Estos conflictos pueden durar hasta dos o tres años. Las normas de la comarca dicen que, si no se pueden poner de acuerdo las comunidades, el problema se trae a la Asamblea General, que asigna una Comisión evaluadora de la situación y presenta una propuesta genera al pleno para una votación general (51 comunidades tienen voto). Una vez tomada la decisión final en la comarca, se adopta una medida para el problema. comarca, un Guna tiene que estar casado con un(a) extranjero(a) y la propiedad nunca puede ir a nombre del extranjero(a) sino a nombre del Guna. Si no están casados, no se puede. Ha habido eventos históricos, casi catastróficos, cuando vinieron extranjeros a alquilar unas islas para hacer turismo y hubo un conflicto entre los extranjeros y los locales $^{11}$. Los extranjeros no quisieron salir de las islas y se acabó la situación con violencia. Nosotros somos pacíficos, pero en esta situación el conflicto demoró años y los extranjeros no respetaron las decisiones de las autoridades de la época. 

J : Muy interesante. Para terminar esta entrevista, podemos reflexionar sobre unos últimas temas de la actualidad en Gunayala... Con el tema de la subida del nivel del mar y de la eventual relocalización de las comunidades isleñas hacia el continente de la comarca o hacia la ciudad, ¿cuál va a ser el impacto sobre el sector turístico ? Sabiendo que el turismo en Gunayala es de mar y playa, ¿cuál será el impacto?

I : Es un tema realista. Somos los primeros en ver la realidad hoy en día de este fenómeno y las autoridades de Gunayala no se han enfocado hasta ahora en este tema. El traslado de la comunidad hacia tierra firme es una iniciativa propia, de algún grupo en la misma comunidad, pero no de la comarca, no del Congreso. El impacto quizás lo vamos a ver dentro de 20 o 30 años. Ya las cosas van avanzando más rápido.

Quizás el turismo que vayamos a tener va a ser totalmente diferente y podría estar vinculado con el tema del cambio climático. Por ejemplo, el turismo podría estar enfocado sobre los traslados de las comunidades, observar cómo viven, cómo ha cambiado todo. Tal vez es el turismo del futuro.

Seguramente habrá un impacto en la dinámica de las playas, que se mueven siempre por el nivel del mar, y vamos a ver un impacto a nivel económico también. Existe una oportunidad, con este problema, que es la de organizar o programar otros tipos de ingresos para la comarca. Lo mejor de todo eso para nosotros es que somos resilientes, nos adaptamos a los cambios. Los humanos somos así. No me imagino la comarca sin un turismo de sol y playa, y el impacto que eso va a tener en las comunidades. Tal vez dentro de 10 a 15 años, otras comunidades van a trasladarse. En 10 años quizás se mueve una más, o dos. No se sabe lo que va a pasar. De las comunidades que piensan trasladarse hoy día, no todos los comuneros quieren mudarse. Los ancianos y abuelos no quieren moverse porque eso es su tierra, su casa. Aunque le diga que se va a hundir, a ellos no les importa. Es algo muy fuerte. Y el tema del cambio climático es algo nuevo para nosotros, apenas los jóvenes están entendiendo un poco más, pero para los que toman las decisiones, para los líderes, es algo incomprensible, algo que no puede ocurrir. Pero los jóvenes sí sabemos que esto está pasando.

$91 \mathrm{~J}$ : ¿Por qué será que no hay turismo de bosque y selva en Gunayala? ¿Los problemas ambientales en la parte insular de la comarca y el tema del cambio climático podrían ser incentivos para iniciar un turismo de bosque?

2 I : Eso sería el objetivo. Pero para eso tenemos que observar las normas. Si tú adoptas el punto de vista de un Guna, tienes que mirar la importancia del ecosistema del bosque. Si es bosque, tienes muchas más restricciones. Se dice que hay muchos conocimientos científicos desconocidos sobre el bosque de la comarca, y los Gunas no quieren que cualquier persona venga y junte ese tipo de muestra o conocimiento. Para poner cámaras trampas, por ejemplo, necesitas un permiso que es muy complicado de obtener.

3 É : ¿Utilizan la palabra patrimonio para hablar de la selva, de las montañas o de las islas?

94 I : Palabra como tal de patrimonio, no. Quizás en Guna. Las montañas ya vienen incluidas en el diario vivir de la cosmovisión desde que eres un bebé. Desde que nace un Guna, los primeros cantos que tienes son que la montaña es tuya, que la tierra es tuya. Pero no una palabra como tal que diga "este es mi patrimonio, es mi propiedad". El Guna lo lleva en su diario vivir, lo tiene desde su nacimiento. En la Ley Fundamental está la palabra, pero no es algo que el Guna común usa. 


\section{NOTES}

1. Division administrativa

2. El primer Congreso de la Juventud Guna fue celebrado en agosto 2017 en la comunidad de Mammidub en Gunayala.

3. Division administrative

4. Le premier Congrès de la Jeunesse Guna fut célébré en août 2017 dans la communauté de Mammidub à Gunayala.

5. El ñeque es un animal

6. Líderes de la comunidad

7. El virus del Zika es causado por la picadura de un mosquito y puede transmitirse al feto. Apareció en 2016 en Latinoamérica.

8. Ver Mónica Martínez Mauri, "Por qué pagar por entrar a Gunayala? Movilidad turística, soberanía y pueblos indígenas en Panamá”, Norois, 247, 2018, 63-76.

9. Líderes de la comunidad.

10. La mola es un vestido guna tradicional, hecho por la mujeres, con diseños geométricos.

11. El caso de los hoteles de los empresarios norteamericanos D. Barton y de T. A. Moody en dos islas de Gunayala. La situación terminó después muchos años de pleitos en tragedia en 1981. (Martínez Mauri, 2010). 


\section{AUTEURS}

\section{JOHANNA DURGET}

License en Études Internationales, Université de Montréal (Canada) - Master en Gestion des territoires et Développement local : Patrimoine naturel, culturel et Tourisme durable, Le Mans Université

\section{ELODIE SALIN}

Maîtresse de Conférences en géographie, Le Mans Université, Laboratoire Espaces et Sociétés (UMR ESO 6590 CNRS), Chercheuse associée EIREST (Equipe interdisciplinaire de Recherche Sur le Tourisme) - Université Paris I Panthéon-Sorbonne 